\section{Ounan vissãต}

soblore 1

\section{riogranmente}

aloss aloentess

\section{unentraiss und}

\section{sissternan}

\section{dúlbliees ale}

\section{sinuide}

“Agora, pro teu prol, eu tenho o intento de levar-te comigo; ir-te-ei

guiando pela estância do eterno sofrimento" (Dante Alighieri) •
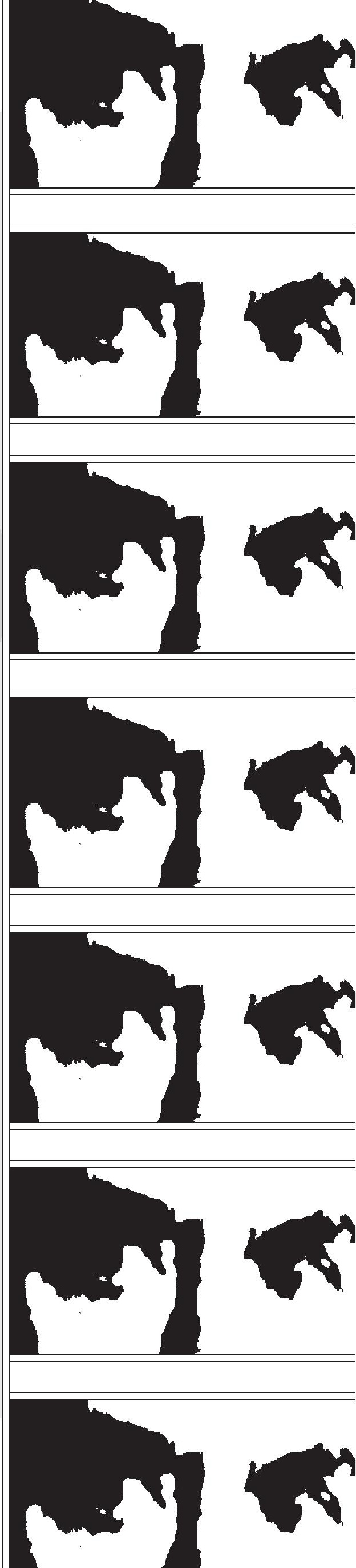
diretor do Instituto de Psiquiatria da UFRJ e estava terminando meu mestrado neste mesmo local. Na época, quase por acaso, prestei concurso no Conjunto Hospitalar do Mandaqui. Para quem chegava a São Paulo era uma oportunidade inicial de poder ficar junto ao ensino, uma vez que esse hospital tinha enfermaria psiquiátrica e a residência médica em psiquiatria estava começando. Terminei meu mestrado em agosto de 1994 e tive a felicidade de ter como orientadora a professora doutora Ana Maria Fernandes Pitta.

Nesse ínterim, a residência do Mandaqui me fazia feliz. Tínhamos muitas idéias e procurávamos a fórmula da formação ideal do residente em psiquiatria. Fórmula essa que procuramos até hoje.

Desde o início, dada a formação diversa dos profissionais que lá estiveram ou ainda estão, passamos por muitos questionamentos, direcionamentos e redirecionamentos. No início havia no ar um certo clima de reforma, de "coisa nova”. O predomínio era de um discurso psicodinâmico, principalmente lacaniano. Eu, particularmente, não me identificava. Atualmente, o referencial é a Psiquiatria Clínica.

\section{AMBIENTE DE TRABALHO}

À medida que o tempo passa, quando se está longe de uma universidade o contato com a realidade social e com os parcos instrumentos de trabalho é inevitável.

Não que acredite que os grandes centros de pesquisa estão, neste momento, munidos de grande ajuda governamental. Mas por aqui a coisa é um pouco mais deficitária.

O Conjunto Hospitalar do Mandaqui funciona na Zona Norte como referência para a psiquiatria de urgência: temos, no pronto-socorro, plantonistas psiquiatras 24 horas por dia, todos os dias. Uma vez atendido no prontosocorro, o paciente pode ser encaminhado, segundo critérios de patologiagravidade, para internação ou para um dos ambulatórios de saúde mental existentes na Zona Norte.

As unidades de internação recebem tais pacientes para um trabalho de internação psiquiátrica diverso entre elas, usando critérios de admissão não homogêneos. Por que não-homogêneos? Ora, é simples, porque jamais houve

LOESTER SILVEIRA RIBEIRO é mestre em Psiquiatria e preceptor de residência médica do Conjunto Hospitalar do Mandaqui. 


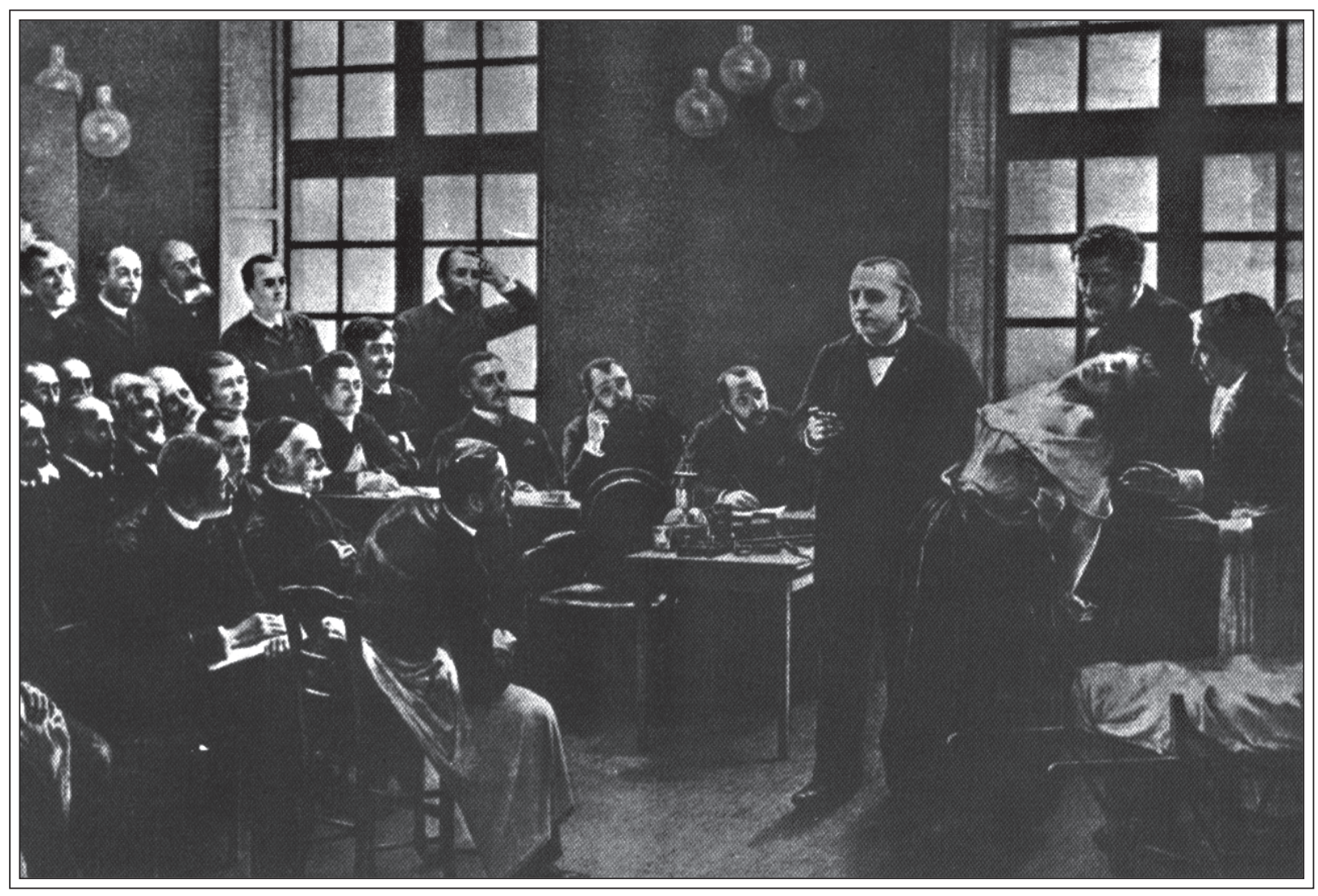

O médico Jean

\section{Martin Charcot}

em uma sessão

de hipnose um consenso de quem deve ser admitido, como e por que, e também porque algumas são particulares conveniadas ao SUS. Portanto, justificando seus critérios e sua forma de abordagem clínica, pela "parca ajuda que recebem como pagamento das diárias", nunca entendi, mas as coisas são assim...

Como já referi anteriormente, temos uma enfermaria para internação de pacientes em crise dentro do Conjunto Hospitalar do Mandaqui (enfermaria psiquiátrica em hospital geral). Nessa enfermaria contamos com 27 leitos disponíveis e procuramos critérios homogêneos para admissão, tratamento e posterior encaminhamento para o tratamento externo. Ainda podemos realizar um trabalho assemelhado à psiquiatria desenvolvida nas universidades. Neste contexto está inserida a atividade de ensino de residentes e aprimorandos de psicologia.

Os ambulatórios de saúde mental do estado na Zona Norte recebem tais pacientes após alta das internações psiquiátricas. Per- cebemos que os mesmos já estão com a capacidade de acolhimento limitada, pois aqueles ambulatórios municipais existentes outrora praticamente desapareceram com o advento do PAS. Todos já previam, todos já anteviam, ninguém pôde fazer nada...-que pena! Então nossos colegas dos ambulatórios de saúde mental do estado fazem o que podem e, às vezes, pouco podem fazer..., mas ainda continuam fazendo.

Observamos que não existem, por aqui, como opções para tratamento, hospitaisdia, centros de reabilitação psicossocial, centros para abrigar aqueles que não possuem famílias, casas de pernoite. Nunca existiram - e assim observamos que há um salto insólito e pouco eficaz - paciente internado-ambulatório de saúde mental ou ambulatório-internação. Então, sem tais recursos intermediários ou fins o tratamento de reabilitação fica cada vez mais prejudicado. Por que isso acontece ?

Nada agradável tambémé constatar que, por aqui, o percurso do doente é inverso. 
Primeiro enlouquece, procura o pronto-socorro e é internado e depois é encaminhado para os ambulatórios. Eu pensava que esse processo pudesse acontecer, pelo menos em boa parte dos casos, ao contrário.

Não dispomos de equipes volantes ou, se preferirem, equipes de atendimento domiciliar diário. A meu ver, poderiam minimizar tais problemas garantindo ao paciente-família a continuidade de tratamentos, orientações e evitar, assim, o ciclo de internações e reinternações. Acredito que seria possível realizar campanhas e ensinar à população noções básicas de detecção precoce (sinais e sintomas) de transtornos mentais.

Discutirei isso a seguir. Por ora fica a indagação e perplexidade: por que o ciclo hospital-ambulatório-hospital e cronificação?

\section{OS USUÁRIOS (PACIENTE-FAMILLA)}

A regra é a miséria em todos os sentidos. A exceção é a abundância. O contexto socioeconômico-cultural em que se insere um paciente que procura atendimento psiquiátrico no serviço público é o da exclusão. Desempregados ou subempregados pacientes e familiares fazem a viacrucis. $\mathrm{O}$ paciente e o familiar, ambos, geralmente, com baixo nível de escolaridade (poucos têm o primeiro grau completo), aceitam de bom grado aquilo que lhes é oferecido (ou imposto) como favor, como "algo de graça”, algo mágico pelo qual eles não pagam nada. Para muitos é um grande alívio a internação. Por quê? Pelo menos 30 dias (ou mais, talvez) de cama, comida e roupa lavada. A família, emocionada, agradece qualquer "Haldol" que acalme. Existe também a aposentadoria por invalidez, que muitos conseguem - um salário mínimo ajuda no orçamento familiar. Facilmente detectamos quando vimos um paciente e seus familiares: iniciantes, ainda não sabem como percorrer esse circo de horrores; veteranos, já sabem que não adianta se desesperar, quando a internação é confir- mada já é a solução por si só.

Assim, nós, médicos, vamos trabalhando. Por aqui a linguagem rebuscada dá lugar a palavras mais simples. Exigir a presença do familiar durante o tratamento é exigir o impossível. Quase sempre observamos que estão ocupados procurando emprego, ou lutando para manter-se no seu miserável e desumano subemprego. "Doutor, não posso ir no grupo de família, senão meu patrão me despede." Falar em suporte familiar e social para a recuperação ou readaptação do doente mental e condições dignas de existência é cinismo. A linguagem aqui é a do possível.

Então, verificamos a ineficácia e a contradição no momento de uma intervenção emergencial no pronto-socorro, quando se indica o encaminhamento para ambulatório. Quem leva? Quem busca? Quem cuida? Quem dá o remédio? Quem consegue a comida? O mesmo raciocínio se aplica para o paciente internado. Ao se deparar com a inevitável "alta hospitalar", o familiar primeiro pergunta: "Será que não dá para ele ficar pelo menos mais uma semana, preciso arranjar alguém para cuidar dele". Portanto, fica, e qualquer tentativa de interação médico-equipe-doente-família é um discurso vazio, para não dizer outra coisa.

A distância que separa o profissional da saúde do paciente e familiar nesse contexto é intransponível. A prescrição de medicamentos que o Estado oferece (nem sempre aqueles que gostaríamos de usar) e a tentativa ortodoxa de psicoterapia (aprendida nos moldes de psicanálise paga) são uma aberração, talvez congruente com o país em que vivemos, mas não com o ser quase humano que tratamos.

\section{O MÉDICO PSIQUIATRA EA ASSISTÊNCIA PSIQUIÁTRICA NA REALIDADE ACIMA DELINEADA}

Tecer críticas e perspectivas é um exercício de futurismo. Mas não é difícil prever 
ou simplesmente constatar a falência geral do sistema. Observamos cada vez mais, no treinamento do médico residente em psiquiatria, a falta de bom senso e a necessidade de mostrar-lhe a dura realidade com que vai se deparar. Vemos um ensino voltado para diagnósticos brilhantes, CID-10, DSM-IV e um direcionamento maciço para a pesquisa. Mas pesquisar o quê? Diagnosticar o quê? E depois, o que faço? Isso não estava nos livros.

Recentemente, admitimos, após concurso público, alguns jovens médicos psiquiatras de renomadas instituições de São Pau1o. Acabaram a residência médica sabendo todos os detalhes de todas as publicações mais recentes. Todos, após 3 meses de trabalho, pediram demissão. O que ocorre? Na teoria eram ótimos e são. Por que não conseguem trabalhar no serviço público? Por que voltam correndo para as universidades?

Não é difícil prever que essa geração precisará mais de universidades e consultórios particulares: se conseguirem as verbas para a pesquisa e os pacientes que pagam, ótimo para eles. Mas continuará ruim para os doentes miseráveis e médicos que não têm essa sorte...

Talvez já ocorra fato bizarro semelhante à "nau dos loucos". Com a falta de profissionais especializados, com o fechamento dos antigos hospícios e com o sucateamento de hospitais públicos e ambulatórios, o que resta? Como já acontece na maioria dos países "em desenvolvimento", a procissão de "loucos” logo estará passeando pela cidade, sem tratamento, sem perspectiva... É uma questão de tempo. Temos uma esperança ainda: quem sabe alguém encontre a cura para as doenças mentais e todos voltem a ser "normais". Mas epidemiologia não mente (pelo menos queremos acreditar) e já podemos vislumbrar um "monte de loucos" sem local adequado para tratamento.

Pensar no SUS como está é triste. Tenho a impressão de que isso possa interessar a alguém. Quem sabe algum plano managed care seja a solução? Mas, e quem não tem emprego para pagar?

\section{REFLEXÕES SOBRE UMA POĹTICA DE ASSISTENNCIA PSIQUIÁTRICA PARA A POPULAÇ̃̃o AQUI ANALISADA}

O SUS surgiu de estudos sérios e bemintencionados . Havia um serviço médico federal, um estadual e um municipal. Para evitar gastos desnecessários, superposição de serviços, desperdícios, etc., foi proposta a unificação. Os recursos seriam somados e se poderia prestar melhor atendimento. Infelizmente, o governo federal se retirou paulatinamente da assistência aos doentes; o governo estadual idem (exceção feita à cidade de São Paulo, pois a ineficácia do PAS não permitiu ainda tal postura do governo estadual) e os municípios receberam de presente os pacientes. Mal-interpretado e posto em prática, o SUS termina por prestigiar procedimentos de alto custo, não faz prevenção, o país está cheio de médicos malformados, os atendimentos encarecem, pois tradicionalmente a incompetência custa caro e vamos afundando nessa areia movediça.

Então entram os planos de saúde. Ganharam dinheiro na instalação e nos primeiros anos, quando os futuros pacientes ainda os usavam pouco. Agora chega sorrateiramente ao país a continuidade da idéia managed care, home care e outros cares.... Como os norte-americanos estão tendo problemas em seu país, ainda vão ganhar algum dinheiro por aqui e depois vão se retirar. Daí, voltaremos à miséria costumeira.

Ouço muito falar no sistema de saúde canadense. Perfeito. Maravilhoso. Todos contribuem, todos têm assistência a tudo. Os médicos são bem pagos e recebem seus salários conforme especialização, tempo de serviço e eficiência pessoal. Por que aqui isso não seria possível? O governo, provavelmente, responderia com a costumeira e madorrenta desculpa: falta de verbas. Os empresários não responderiam, fariam lobby contra. Acredito que falta vontade 
política para mudar; muitos lucram com tamanha desgraça na saúde.

O SUS, como está, não pode continuar. Está na hora de um grande debate nacional. Que saúde queremos? Todos os dias aparecem histórias de pessoas morrendo à margem do sistema. Falta verba para antibióticos; é mais fácil amputar um pé do que tratá-lo; é mais fácil arrancar um dente do que tratá-lo. Um doente mental debaixo da ponte estaria exercendo sua cidadania? Vivemos em um mundo de aparências. Todo mundo faz de conta.

Creio que a saída não é complexa. Porém, nem por isso é simples. Não devemos continuar copiando o sistema americano de planos de saúde privados. Não está dando certo para eles. O brasileiro cada vez menos pode pagar por um plano de saúde ou equivalente. Usar como paradigma o sistema canadense é utopia. Existem claras diferenças - de renda per capita, de desenvolvimento e culturais - para pensarmos nesse tipo de filosofia no Brasil. Pelo menos por enquanto.

Acredito que com uma certa boa vontade poderíamos:

a) Aproximar os profissionais de saúde da comunidade. Diante da dificuldade de doentes e familiares de irem até o atendimento, o atendimento seria deslocado para os locais necessários. Esse trabalho teria que ser permanente, preventivo e curativo.

b) As universidades teriam que sair em campo (literalmente). Pesquisas deveriam ser feitas nas comunidades. Mas só isso não basta. A devolutiva deveria ser trabalho prestado, não teses e mais teses que preenchem as bibliotecas e dão títulos de docentes. A pós-graduação teria que dar uma contrapartida prática para a população.

c) Alguns estágios de residência médica deveriam ser feitos na casa do paciente. Não proponho com isso apenas a psiquiatria social, ao contrário, a clínica deveria ser exercida no local da doença. Assim deixaríamos apenas os casos mais complexos para internações e tratamentos de ambulatórios, hospital-dia e centros de ressocialização.

d) As pesquisas científicas devem continuar e as verbas também. Porém, repetindo, poderíamos incentivar cada vez mais quem pesquisa, dando assistência concomitante a tratamento aos mais carentes. Isso é possível e em nada diminuiria a qualidade destas, pelo contrário. Talvez tivéssemos dados epidemiológicos brasileiros e não precisaríamos recorrer à literatura internacional para obtê-los.

Concluindo, tudo o que citei acima é possível. Pouco se gastaria. Só precisaríamos saber a quem incomodariam tais mudanças. Comecei minha narrativa citando a Zona Norte de São Paulo, porém, penso que tais idéias se aplicariam a todo o país.

Intencionalmente não elaborei este texto nos moldes de uma publicação científica. Acredito ser mais fiel ao conteúdo relatar desta forma. 